\title{
Criação e autoria nas culturas tradicionais desde a Teoria Histórico-Cultural
}

\author{
Saulo Pequeno, (D) Daniela Barros, (D) Patrícia Lima Martins Pederiva \\ Universidade de Brasília, Brasília, DF, Brasil
}

\begin{abstract}
Resumo
As expressões culturais tradicionais sofrem constante subalternização a partir da organização eurocêntrica e colonial, que as deslegitima em seus saberes, cosmologias e modos de ser e viver. $O$ não enquadramento na noção hegemônica de autoria individual nas normas de propriedade intelectual e direitos autorais é uma das formas com que esta subalternização acontece. O entendimento hegemônico de criação é pautado pela ideia moderna de indivíduo. Entretanto, os processos de criação nas expressões culturais tradicionais são coletivos e coincidem com seus processos educativos. O objetivo deste trabalho é propor, a partir da teoria histórico-cultural de Vigotski, um outro olhar para os processos de criação, sob a perspectiva de que pessoa e meio social formam uma unidade indivisivel. O texto apresentado é parte de tese de doutorado em educação, de caráter teórico, e concentra suas discussões nas assimetrias entre a autoria individual e o caráter coletivo do ato criador. Conclui-se que não basta a revisão dos mecanismos legais de proteção autoral, mas é necessária uma inversão na lógica hegemônica que embasa tais instrumentos. Propõe-se como caminho um outro entendimento de criação e educação, que reconheça a expressão autêntica das pessoas detentoras de expressões culturais tradicionais.
\end{abstract}

Palavras-chave: criação; autoria; educação; expressões culturais tradicionais; teoria histórico-cultural.

\section{Creation and authorship in the traditional cultures from Historical-Cultural Theory}

\begin{abstract}
The traditional cultural expressions are constantly subalternized by the colonialism and eurocentrism, that delegitimizes their knowledges, cosmologies and ways of being and living. One of this subalternizing practices is the impossibility of claiming intellectual property rights and copyrights, once these laws are based on the hegemonic idea of individual authorship. The hegemonic understanding of creation comes from the modern idea of individual. The objective of this paper is to propose, through the cultural-historical theory of Vigotski, a different approach of the creation process, outlining the perspective that a person and the social medium are an indivisible unity. The paper is a fragment of a theoretical doctoral thesis in Education, and focuses the discussion on the asymmetries between the individual authorship and the collective aspect of the creation act. It concludes that the review of laws is not enough, but there's the necessity of inverting the logic of the hegemonic paradigm. The text proposes another way to understand creation and education, one that recognizes the authentic expression of the traditional cultural expression's holders.
\end{abstract}

Keywords: creation; education; authorship; traditional cultural expressions; cultural-historical theory.

\section{Introdução}

Este artigo apresenta discussão entre o contexto das expressões culturais tradicionais e a educação na perspectiva da teoria histórico-cultural, a partir do conceito de criação e conflitos sobre autoria. As questões autorais de propriedade intelectual são problemas históricos para detentores de tradições culturais, em que a exploração de suas criações sustenta a exploração, espetacularização e hierarquização de seus saberes, manifestações artísticas, cosmologias e epistemes, além de fortalecer as assimetrias sobre suas condições de vida e manutenção de suas tradições e modos de viver.

Os termos "expressões culturais tradicionais" e "expressões do folclore" são usados como sinônimos nas discussões de política internacional sobre a área da propriedade intelectual. "Expressões culturais tradicionais" (ou ECTs) é usado como um termo neutro nesta seção, porque algumas comunidades expressaram reservas quanto às conotações negativas da palavra "folclore" (WORLD INTELLECTU-

\footnotetext{
^Endereço para correspondência: Universidade de Brasília, Programa de Pós-Graduação da Educação - PPGE/UnB. Endereço: SCRN 716 Bloco G Entrada 42 Apt. 503, Brasília - DF CEP: 70.770-670.E-mails: saulopequeno1@gmail. com, danibps@gmail.com, pat.pederiva@gmail.com

Os dados completos dos autores encontram-se ao final do artigo.
}

AL PROPERTY ORGANIZATION [WIPO], 2008, p. 57, tradução nossa)

Os conflitos autorais indicam, além da dificuldade no agenciamento de direitos, a diferença da própria compreensão das pessoas em relação a seu meio, possibilitando a investigação dos processos educativos que acontecem nos contextos de expressões culturais tradicionais e seu caráter psicológico. Este é o tema de tese de doutorado em andamento, ${ }^{1}$ de caráter teórico, que tem por objetivo examinar a relação pessoa-meio social característica dos processos de criação de expressões culturais tradicionais. Este artigo, como recorte de tais reflexões, discute a relação entre a noção de autoria individual, o conceito de criação segundo a teoria histórico-cultural e os processos educativos no contexto das expressões culturais tradicionais.

\section{Criação e educação como unidade pessoa-meio social pelo olhar histórico-cultural}

A autoria individual como sinônimo de criação é uma característica do mundo moderno e tem sua origem histórica na Idade Média europeia, quando da transformação na relação com a leitura e a escrita de textos, a

O presente trabalho foi realizado com apoio da Coordenação de Aperfeiçoamento de Pessoal de Nível Superior - Brasil (CAPES) - Código de Financiamento 001. 
partir das mudanças na tecnologia do alfabeto (ILLICH, 2002; BURKE, 2003). Esta gênese histórica fundamenta a concepção moderna e hegemônica de criação, como sinônimo de processo individual-autoral, submetendo, pela normatização, as relações com o saber ao paradigma hegemônico eurocêntrico de indivíduo e autoria.

No que diz respeito à propriedade intelectual, são os direitos autorais que regulam o campo de criações artísticas, intelectuais e performáticas. Segundo este marco regulatório e conceitual é que se reconhece o que é uma criação original, e o que se entende pela noção de autoria, que determina quem tem ou não legitimidade de agenciar e defender uma criação. Entretanto, segundo a Organização Mundial da Propriedade Intelectual, as expressões culturais tradicionais são transgeracionais e de origem desconhecida, de forma que "não são protegidas pelas leis de direitos autorais atuais e são tratadas, pela perspectiva do sistema de propriedade intelectual, como parte do 'domínio público"” (WIPO, 2008, p. 58, tradução nossa).

Há uma diferença epistêmica entre aquilo que a propriedade intelectual reconhece por autoria e criação, como o resultado do esforço de um único indivíduo, em contraposição ao exercício da herança coletiva e compartilhada de expressões tradicionais. Entretanto, segundo a teoria histórico-cultural, as pessoas em seus processos de criação utilizam elementos e experiências que não partem de si, que não são inéditos, criados por outros e que, portanto, possuem caráter coletivo.

No livro Psicologia da Arte, originalmente publicado em 1925, Vigotski (1999, p. 15) já abordava a tensão entre o que se considera criação individual (ligada a autores), e a criação coletiva (ligada a culturas populares), afirmando que os processos de criação humana não possuem características essenciais diferentes entre si: "De fato, o antigo ponto de vista, segundo o qual existiria uma diferença de princípio entre os processos e os produtos da criação popular e individual, parece hoje abandonado por unanimidade".

A teoria histórico-cultural opõe-se à ideia de que detentores de tradições populares possuem saberes, práticas e compreensões rudimentares ou simplórias. Pelo contrário, são "donos da técnica do seu ofício", exímios representantes de suas culturas e heranças. O movimento das tradições, em constante transformação, não é consequência do acaso, mas da ação de seus detentores localizados cultural e historicamente. Não há, portanto, hierarquia entre os processos de criação.

[...] é absolutamente falsa a concepção segundo a qual a poesia popular surge sem artifícios e é criada por todo o povo e não por profissionais - narradores, cantores, fabuladores e outros profissionais da criação artística - donos da técnica do seu ofício, rica e profundamente especializada, da qual fazem uso exatamente como os escritores das épocas mais tardias (VIGOTSKI, 1999, p. 16).

Segundo Vigotski (1999), a hierarquização não é possível, porque não há diferenças qualitativas entre os processos, mas quantitativas no que diz respeito ao caráter das elaborações no processo criador. Desta forma, a autoria individual é, apenas, um momento individual do pro- cesso total de criação - que é coletivo na sua gênese. $\mathrm{Ou}$ seja, da mesma forma que detentores de expressões culturais tradicionais herdam seus contos, seus pontos, suas técnicas, suas estéticas, estilos, ferramentas etc., autores individuais também herdam das suas próprias culturas.

Se quiséssemos calcular o que, em cada obra de arte literária, foi criado pelo próprio autor e o que ele recebeu já pronto da tradição literária, observaríamos com muita frequência, quase sempre, que deveríamos atribuir à parte da criação pessoal do autor apenas a escolha desses ou daqueles elementos, a sua combinação, a variação, em certos limites, dos lugares-comuns, a transferência de uns elementos da tradição para outros sistemas. [...] A diferença está apenas na correlação quantitativa desses dois momentos. [...] O caminho do nadador, como a obra do escritor, será sempre a resultante de duas forças - dos esforços pessoais do narrador e da força deslocadora da corrente. Temos todos os fundamentos para afirmar que, do ponto de vista psicológico, não há diferença de princípio entre os processos de criação popular e individual (VIGOTSKI, 1999, p. 16).

$\mathrm{O}$ reconhecimento do momento individual na criação de uma expressão tradicional permite entender que aquilo que é coletivo não é desgovernado ou sujeito a interferências que escapam às pessoas detentoras daquela tradição, mas, pelo contrário, detentores de expressões tradicionais são aqueles que interferem e se responsabilizam pelas suas heranças e criações.

Entretanto, quando se atribui a uma criação o caráter exclusivamente individual, toma-se uma parte do processo como a sua totalidade. No reconhecimento social dos processos de criação como autoria individual, a ideia de uma obra acabada, definitiva, separa o autor da contribuição coletiva à sua obra. No caso das expressões culturais tradicionais, suprime o diálogo com o presente, ou seja, com os movimentos e transformações que permitem a continuidade dessas tradições (BARROS, 2017).

Desta forma, a noção de indivíduo autoral representa o homem de cultura universal, hegemônico, que, no emprego supremo de seus atributos racionais, é capaz de desvendar o mundo de seus mistérios e suas superstições, apresentando objetivamente a Verdade. Quando se institui uma Verdade, todas as formas e maneiras diversas de conceber os saberes e as relações cosmológicas com o mundo são, necessariamente, desacreditadas, equivocadas ou subordinadas à nova Verdade, hegemônica. $\mathrm{O}$ modo do indivíduo moderno se relacionar com a história está fundamentado na atitude de reescrevê-la, de racionalidade positivista (BARTHES, 2004).

A criação autoral, de acordo com o modelo hegemônico do indivíduo moderno, deve conter início, meio e fim, apresentando um conjunto acabado e coerente de leitura do mundo. Assim, uma obra não admite caráter transitório, passível de modificações; não pode ser objeto de transformação e adaptação por outras pessoas, ou seja, não pode ser objeto de criação coletiva. Em suma, a obra do indivíduo moderno deve ser registrada, registro este que significa a versão final, acabada, da sua criação. 
Nas culturas tradicionais aquilo que se chama de dimensões performáticas, cosmológicas, filosóficas, de visão de mundo, também apresentam um todo coerente. Entretanto, este todo coerente, quando captado por algum registro, não é um arremate conclusório, definitivo e soberano. O movimento das tradições é perene e, portanto, não há uma versão final. Pode-se apenas realizar o registro de um determinado momento histórico.

A manifestação externa da criação diz respeito ao que se torna passível de materialização, como objetos, desenhos e palavras etc., e também se refere a exteriorizações não materiais como sons, músicas, movimentos corporais, versos e prosas faladas, ideias comunicadas etc. Mas a criação não se limita a expressões externas. As criações internas dizem respeito aos sentimentos, às novas formas de conduta, a correlações práticas e conceituais etc. Se manifestam na personalidade da pessoa, organizando-a e alterando-a e, de certa forma, se inscrevem no aspecto interno da pessoa de forma mais plena do que a sua exteriorização seria capaz de informar.

Na teoria histórico-cultural, "chamamos de atividade criadora do homem aquela em que se cria algo novo. Pouco importa se o que se cria é algum objeto do mundo externo ou uma construção da mente ou do sentimento, se conhecida apenas pela pessoa em que essa construção habita e se manifesta" (VIGOTSKI, 2009, p. 11). Esta concepção sobre criação possui implicações para a educação, ao reconhecer que a criação não se refere somente a objetos externos. Os processos educativos, como ato de elaboração de novos conhecimentos, novas formas de comportamento, novas formas de percepção de si e do mundo, baseadas na experiência anterior, são processos de criação interna, e são objeto de esforço da própria pessoa que se desenvolve.

[...] a atividade criadora da imaginação depende diretamente da riqueza e da diversidade da experiência anterior da pessoa, porque essa experiência constitui o material com que se criam as construções da fantasia. Quanto mais rica a experiência da pessoa, mais material está disponível para a imaginação dela. [...] A conclusão pedagógica a que se pode chegar com base nisso consiste na afirmação da necessidade de ampliar a experiência da criança, caso se queira criar bases suficientemente sólidas para a sua atividade de criação. Quanto mais a criança viu, ouviu e vivenciou, mais ela sabe e assimilou; quanto maior a quantidade de elementos da realidade que ela dispõe em sua experiência - sendo as demais circunstâncias as mesmas -, mais significativa e produtiva será a atividade de sua imaginação. [...] A atividade combinatória do nosso cérebro não é algo completamente novo em relação à atividade de conservação, porém, torna-a mais complexa (VIGOTSKI, 2009, p. 22-23).

A imaginação, neste sentido, representa o novo pela sua combinação inédita, e é uma alavanca para novas sínteses e combinações. Tudo aquilo que envolve a atividade de uma pessoa tem duplo caráter, na medida em que as experiências e criações possuem a possibilidade de se manifestar externa e internamente. A criação diz respeito então tanto à elaboração de algo novo, quanto à conservação da experiência.
Os hábitos, experiências, línguas, objetos, comportamentos, ambientes, tudo aquilo que compõe a vida de uma pessoa, desde os primeiros momentos da infância, constituem as suas experiências e viabilizam, de acordo com a trajetória particular de cada um, suas necessidades e possibilidades de criação.

Os processos de criação, portanto, estão ligados ao trabalho da memória e da imaginação, a partir das experiências já existentes. Nesse sentido, um objeto novo, ou uma ideia nova, são uma determinada contribuição sobre um objeto ou ideia anteriores. Daí que a criação é um ato processual, cumulativo, representativo da herança do mundo e da ação sobre esta herança, uma atividade de todos.

Vigotski (2009) considera que a ideia cotidiana de criação, ligada a um dom de poucos cujo resultado são obras-primas feitas por gênios, não corresponde à concepção da teoria histórico-cultural. A noção de criação como um privilégio de poucos possui consequências radicais para a educação. Se uma pessoa acredita que não cria, não pode acreditar que possui papel ativo e responsabilidade sobre algo que caracterize o surgimento do novo, que pode manifestar-se tanto externamente para o mundo, quanto internamente para si.

Estabelecer a legitimidade de criação, para poucos, significa considerar que o surgimento do novo também é pertencente a poucos, desconsiderando então as criações da vasta maioria. Significa romper com o aspecto coletivo que caracteriza o caráter relacional da existência, em que a criação é um atributo do ser humano. A criação é a síntese do esforço coletivo, que alicerça a parcela do esforço individual.

Atribuir uma característica individualizada à educação, à criação e à própria existência significa raptar a pessoa de sua história e cultura, colocando sobre ela o peso de significar o mundo inteiro por si só.

A teoria histórico-cultural estabelece, ainda, que a relação entre a imaginação e as emoções também compõe os processos de criação, ou seja, os sentimentos afetam a imaginação. E, da mesma forma com que os sentimentos afetam a imaginação, também a imaginação afeta o sentimento:

Entretanto, existe ainda uma relação inversa entre imaginação e emoção. Enquanto, no primeiro caso que descrevemos, os sentimentos influem na imaginação, nesse outro, inverso, a imaginação influi no sentimento. Esse fenômeno poderia ser chamado de lei da realidade emocional da imaginação. A essência dessa lei é formulada por Ribot do seguinte modo: "Todas as formas de imaginação criativa contêm em si elementos afetivos" Isto significa que qualquer construção da fantasia influi inversamente sobre nossos sentimentos e, a despeito de essa construção por si só não corresponder à realidade, todo sentimento que provoca é verdadeiro, realmente vivenciado pela pessoa, e dela se apossa (VIGOTSKI, 2009, p. 28).

$\mathrm{Na}$ via contrária, a proposta de vida e conhecimento, baseada no indivíduo moderno e na autoria individual, ignora esse aspecto fundamental dos processos de criação. O colonialismo ocidental dividiu a ciência e a vida prática como atributos da racionalidade, e colocou em 
patamar inferior o campo dos afetos, incluindo todas as demais dimensões da vida como as cosmologias, corporeidades, esteticidades e etnicidades.

Invertendo a lógica hegemônica, o reconhecimento de que nas experiências na cultura se alicerçam as bases do desenvolvimento humano, e que delas provêm os elementos para a criação, significa entender que as pessoas, e a sua ação com/sobre o mundo como criação, compõem uma unidade indivisível entre si e seu meio.

\section{Criação nas expressões culturais tradicionais como processo educativo contra-hegemônico}

Nos contextos de expressões culturais tradicionais, os processos de criação que proporcionam a exteriorização das manifestações coincidem com os seus processos educativos (PEQUENO, 2015). Estes processos fundamentam a forma como as pessoas são recebidas pelas experiências que compõem o seu ambiente e, reconhecendo-se como atuantes em sua história e personalidade, tratam também da forma como as pessoas criam sobre/com sua cultura.

Por exemplo, no contexto da cantoria de viola (SANDRONI, 2007), argumentando sobre a ética das duplas de cantadores, o movimento parte de aspectos melódicos existentes em sua tradição, com a liberdade de colocar sobre tais a originalidade de cada pessoa em sua expressão.

A cantoria de viola, esta maravilhosa arte de improvisação poética cantada, desenvolvida no Nordeste do Brasil, funciona, como mostrou Elizabeth Travassos (1999), segundo uma lógica totalmente incompatível com a lógica do direito autoral. Isto, por duas razões. Primeiro, as melodias das suas improvisações poéticas são usadas por cantadores de maneira totalmente livre. Uma dupla de cantadores vai usar um repertório de melodias como bem entender, sem ter que pagar e sem ter que pedir permissão para alterá-lo. O mourão, o galope, o martelo, entre tantas outras, são modalidades poético-melódicas empregadas pelos cantadores, e concebidas como pertencentes a certo "domínio público". Mas qual é esse "domínio público”? É o domínio da própria comunidade de cantadores, pois entre eles, cantadores de viola, existe um acordo tácito de que podem usar essas melodias e partindo delas criar novas melodias que vão ser usadas pelos pares de uma maneira igualmente livre. Essa é a primeira razão pela qual a lógica do direito autoral, com seu corolário que é a noção de plágio, não se aplica à cantoria de viola [...] (SANDRONI, 2007, p. 74).

É possível perceber o movimento característico dos processos de criação pelo seu caráter psicológico. A expressão de cada pessoa, a maneira como manipula os instrumentos, os aspectos harmônicos, rítmicos e melódicos não são uma originalidade absoluta, como se negasse as contribuições anteriores. Pelo contrário, são esses elementos que identificam a cantoria como parte da sua tradição, reverenciando a contribuição coletiva anterior, sem que isto signifique, entretanto, que não haja a originalidade e singularidade de quem executa. Sandroni (2007, p. 75) continua:

A segunda razão, é que a ética do cantador de viola nunca vai permitir que ele repita a criação verbal do outro cantador - e não precisa haver nenhuma legislação sobre isso. Pois o cantador de viola necessariamente, e por definição, cria de improviso seus versos. Ele usa uma melodia que já foi usada quinhentas vezes e cria versos que só serão usados uma vez. Pelos dois lados, da melodia e do verso, a gestão da propriedade intelectual, na cantoria de viola, não tem nada a ver com a lógica do direito autoral. No entanto, quando melodias e versos dos cantadores de viola são usados por pessoas que não são por eles consideradas como pares, tudo fica diferente. É o caso dos artistas da chamada MPB.

O que se coloca como ética do cantador de viola não pode ser limitado somente à maneira de executar músicas nesta manifestação artística. Como ética, é uma forma de conduta, é forma de ser e estar no mundo. Não se pode admitir que duplas de viola não conhecem a maneira autoral individual de estar no mundo, ou como se o seu comportamento nunca tenha aspectos de conduta individual para suas criações. As diferentes formas, da cultura tradicional da cantoria de viola e da cultura moderna autoral, fazem parte do encontro colonial que caracteriza a cultura destes detentores, com todas as suas contradições e assimetrias.

São as relações sociais que se estabelecem em meio às pessoas detentoras da tradição cultural que possibilitam o processo educativo, para que a característica da performance musical, exterior à pessoa, se torne ética da pessoa, caracterizando o seu comportamento. O contato com as pessoas mais velhas da tradição, a observação dos toques, a escuta das melodias e harmonias e os muitos ensaios não se dão somente pelo aspecto técnico de execução, num vácuo social. Pelo contrário, todas essas atividades são significadas pela cultura tradicional e, por sua vez, contribuem também para a significação do mundo.

Outro exemplo vem do contexto da Festa do Divino Espírito Santo, de Pirenópolis (GO), onde os personagens mascarados são um dos ícones visuais. As imagens mais tradicionais são as máscaras de cara de boi, e o que caracteriza a sua confecção é a produção artesanal feita na própria cidade. Pequeno $(2015$, p. 71$)$ relata a forma com que dois jovens, netos de um dos mestres artesãos da cidade, passaram a confeccionar máscaras:

Os dois netos de Seu Lucinho "P. H." e "J. P." estão com 11 e 14 anos em 2015, mas fizeram as suas primeiras máscaras com 6 e 9 anos, respectivamente. Como os netos estão frequentemente na casa dos avós para passar o dia e a atividade de Seu Lucinho é fazer máscaras, foi desta maneira que começaram a observá-lo, a participar de alguma maneira e ajudá-lo, até se aventurarem a fazer as próprias máscaras.

Segundo o autor, os netos do artesão Lucinho, mesmo com pouca idade e experiência se comparados com o avô, são considerados por ele e pela comunidade local como artesãos de máscaras.

Ao mesmo tempo que aprendiam a fazer máscaras e criavam segundo suas próprias experiências, passavam a fazer parte legitimamente daquele grupo de pessoas que articula as tradições da cidade, por fazerem as máscaras de papel baseadas nas referências simbólicas da comunidade. Segundo Seu Lucinho, a legitimidade dos netos com 11 e 14 anos de idade para a confecção de máscaras é a mesma que a dele, que tem 49 anos de experiência como artesão (PEQUENO, 2015, p. 81). 
Pode-se perceber como se organizam ambientes educativos tradicionais. Não é preciso ser artesã ou artesão experiente para ser detentor, mas sim o reconhecimento da sua comunidade. É no processo de tentativa e experimentação que as pessoas descobrem a sua relação com a criação coletiva precedente, e a singularidade da expressividade de cada detentor. Quando cada pessoa exercita sua expressão, imprime nela sua singularidade e coloca, para suas tradições, novas formas de se apresentar, de forma que coincidem os processos de criação e de educação.

Nas expressões culturais tradicionais os processos educativos não estão ligados somente à recepção de conhecimentos racionais, mas indissociados do caráter ativo, de colocar-se como detentor e expressar-se como parte constituinte das tradições, ligando o passado ao presente e futuro. Esta forma de perceber as tradições e perceber-se nelas não guarda relações com a ideia de autoria individual, em que o ato criador impulsionado para o futuro silencia as contribuições coletivas anteriores. Por estas evidências conclui-se que nas expressões culturais tradicionais não há rompimentos, mas uma educação que possibilita a unidade entre pessoa e meio social, exercitada e exercida cotidianamente.

A força de argumentação da psicologia histórico-cultural de Vigotski está na sua perspectiva sobre os processos de criação, que proporcionam um outro olhar, para além das assimetrias culturais e coloniais impostas às tradições culturais por meio de sua espetacularização e canibalização.

Como exposto, para Vigotski, em todo processo de criação existe o momento coletivo, das heranças culturais, acúmulos de saberes, conhecimentos e formas de vida, que alicerçam o momento individual, que é a expressão singular de cada pessoa a partir da cultura que a constitui.

As duplas cantadoras de viola aproveitam-se das heranças rítmicas, melódicas e harmônicas coletivas que as precedem, e expressam-se de maneira autêntica. Os artesãos de máscaras de Pirenópolis partilham das referências históricas da cidade sobre quais imagens são representadas, mas os resultados de suas criações diferenciam a interpretação de cada artesã e artesão. Da mesma forma, no contexto moderno eurocêntrico, uma criação também se aproveita do acúmulo cultural coletivo das tradições e convenções linguísticas, estéticas, melódicas, técnicas e científicas, para a criação de novas coisas e ideias.

Portanto, à luz da teoria histórico-cultural, a ideia de autoria individual toma a parte do processo, o momento individual, pelo seu todo. Significa subtrair da educação, das relações sociais e da constituição das pessoas, o exercício constante da sua coletividade, proporcionando comportamentos menos sensíveis e comprometidos com a coletividade, com o processo histórico, com formas autênticas de expressão individual em meio à cultura. A partir das expressões culturais tradicionais em diálogo com a teoria histórico-cultural é possível vislumbrar uma outra noção de criação, contra-hegemônica, como base para o entendimento maior do sentido de educação: a educação, por meio da criação como base da existência plural dos modos de viver, ser e estar.

\section{Considerações finais}

$\mathrm{O}$ artigo apresentou a maneira com que o caráter hegemônico da autoria individual, como sinônimo do processo de criação, determina a impossibilidade de agenciamento de direitos autorais para as expressões culturais tradicionais. Isto manifesta, também, as assimetrias que se impõem aos diferentes modos de vida em suas concepções de pessoa, de coletividade e de criação na cultura.

O texto teve por objetivo evidenciar que não basta uma revisão sobre estes ou aqueles mecanismos legais, mas caminhos de discussão que reconheçam seus processos educativos, ou seja, as formas com que as pessoas se desenvolvem, como passam a agir e perceber o mundo nos contextos tradicionais, proporcionando outros paradigmas, que reconheçam a expressão autêntica das pessoas e de suas comunidades. Para tanto, propõe a abordagem da teoria histórico-cultural, que compreende os processos de criação como coletivos em sua essência, como possibilidade para um outro entendimento de educação e criação.

\section{Informações sobre os autores:}

\section{Saulo Pequeno}

\section{(iD) https://orcid.org/0000-0003-1986-5795}

(9) http://lattes.cnpq.br/4438511067969591

Doutorando em Educação pelo Programa de Pós-Graduação em Educação - PPGE da Universidade de Brasília - UnB. Mestre em Educação pelo Programa de Pós-Graduação em Educação da Universidade de Brasília. Bacharel em Ciências Sociais com habilitação em Antropologia pelo Departamento de Antropologia - DAN/ICS da Universidade de Brasília. Pesquisador do GEPPE/ FE/UnB - Grupo de Estudos e Pesquisas em Práticas Educativas (Grupo de Pesquisa certificado pelo CNPq). Pesquisador do Grupo de pesquisa Educação, Saberes e Decolonialidade (Grupo de Pesquisa certificado pelo CNPq).

\section{Daniela Barros}

\section{(iD) https://orcid.org/0000-0002-9324-8747} tp://lattes.cnpq.br/4848853812639285

Doutoranda em Educação pelo Programa de Pós-Graduação em Educação da Universidade de Brasília - PPGE/FE/UnB. Mestre em Educação pelo Programa de Pós-Graduação em Educação da Universidade de Brasília - PPGE/FE/UnB. Pedagoga pela Faculdade de Educação da Universidade de Brasília - FE/UnB. Integrante pesquisadora do Grupo de Estudos e Pesquisas em Práticas Educativas - GEPPE/PPGE/FE/UnB (Certificado pelo CNPq). Pesquisadora do Grupo de Pesquisa Educação, Saberes e Decolonialidades - GPESDecolonialidades/PPGE/FE/UnB (Certificado pelo CNPq). Possui trabalhos realizados no campo da Educação, a partir da Teoria Histórico-Cultural e do Pensamento Decolonial.

\section{Patricia Lima Martins Pederiva \\ (iD) https://orcid.org/0000-0003-4434-6671 \\ (9) http://lattes.cnpq.br/6354485124876296}

Licenciatura em Música pela Universidade de Brasília (1987); Especialização em Execução Musical pela Universidade de Brasília (2000); Mestrado em Educação (Ensino-aprendizagem) pela Universidade Católica de Brasília (2005); Doutorado em Educação pela Universidade de Brasília (2009/ Escola, Aprendizagem e Trabalho Pedagógico); Pós-Doutorado no Departamiento de Psicologia Evolutiva y Educación de la Universidad Autónoma de Madrid, España; Professora do Departamento de Métodos e Técnicas da Faculdade de Educação da Universidade de Brasília; Professora do PPGE- Programa de Pós-Graduação em Educação da UnB na Linha de Pesquisa EAPS (Ensino, Aprendizagem, Desenvolvimento e Subjetividade na Educação), no Eixo de 
Pesquisa de Processos de Escolarização; Coodenadora do GEPPEGrupo de Estudos e Pesquisas em Práticas Educativas(Certificado pelo CNPq); Pesquisadora de Teoria Histórico-Cultural de Lev Semionovich Vigotski.

\section{Contribuições dos autores}

Todos os autores colaboraram ao longo do processo de escrita, desde a elaboração até a revisão. O texto é recorte de tese de doutoramento do autor Saulo Pequeno, responsável pela ideia do artigo, escrito e editado para tal formato em parceria com a autora Daniela Barros na escrita, desenho e discussão, sob orientação da autora Patrícia Pederiva, que participou na escrita, discussão e supervisão. Todos os autores participaram na aprovação da versão final do artigo.

\section{Como citar este artigo:}

\section{ABNT}

PEQUENO, Saulo; BARROS, Daniela, PEDERIVA, Patricia Lima Martins. Criação e autoria nas culturas tradicionais desde a Teoria Histórico-Cultural. Fractal: Revista de Psicologia - Dossiê Psicologia e epistemologias contra-hegemônicas, Niterói, v. 31, n. esp., p. 208-213, set. 2019. https://doi.org/10.22409/1984-0292/ v31i esp/29002

\section{APA}

Pequeno, S., Barros, D., \& Pederiva, P. L. M. (2019, set.). Criação e autoria nas culturas tradicionais desde a Teoria HistóricoCultural. Fractal: Revista de Psicologia - Dossiê Psicologia e epistemologias contra-hegemônicas, 31(esp.), 208-213. doi: https:// doi.org/10.22409/1984-0292/v31i esp/29002

\section{Referências}

BARROS, Daniela. Educação, resistências e tradição oral: a transmissão de saberes pelas oralidades de matriz africana nas culturas populares, povos e comunidades tradicionais. 2017. Dissertação (Mestrado) - Programa de Pós-Graduação em Educação da Universidade de Brasília, Brasília, 2017.

BARTHES, Roland. O rumor da língua. São Paulo: Martins Fontes, 2004

BURKE, Peter. Uma história social do conhecimento: de Gutenberg a Diderot. Tradução de Plínio Dentzien. Rio de Janeiro: J. Zahar, 2003.

ILLICH, Ivan. Em el viñedo del texto: Etología de la lectura: un comentario al "Didascalicon" de Hugo de San Víctor. México DF: Fondo de Cultura Económica, 2002.

PEQUENO, Saulo. Educação, criação e autoria nas manifestações tradicionais das culturas populares: as manifestações da Festa do Divino de Pirenópolis - GO. 2015. Dissertação (Mestrado) - Programa de Pós-Graduação em Educação da Universidade de Brasília, Brasília, 2015.

SANDRONI, Carlos. Propriedade intelectual e música de tradição oral. Revista Cultura e Pensamento, n. 3, p. 64-79 dez, 2007.

VIGOTSKI, Lev Semyonovich. Psicologia da arte. Tradução de Paulo Bezerra. São Paulo: Martins Fontes, 1999.

VIGOTSKI, Lev Semyonovich. Imaginação e criação na infância. Tradução de Zoia Prestes. São Paulo: Ática, 2009.

WORLD INTELLECTUAL PROPERTY ORGANIZATION. WIPO Intellectual Property Handbook: Policy, Law and Use. $2^{\text {nd }}$ ed. Geneva: WIPO, 2008. Available at: https://www.wipo. int/edocs/pubdocs/en/intproperty/489/wipo_pub_489.pdf. Access on: Jan 22. 2018 